\title{
Method Considered Distortional-local Interaction Buckling for Bearing Capacity of Channels with Complex Edge Stiffeners and Web Stiffeners under Axial Compression
}

\author{
Chungang $\mathrm{WANG}^{1, \mathrm{a}}$ and $\mathrm{Yu} \mathrm{BAI}^{1, \mathrm{~b}}$ \\ ${ }^{1}$ Shenyang Jianzhu University, Shenyang, Liaoning China \\ aralphsy@163.com, bbai0409yu@sohu.com
}

\begin{abstract}
Using the current direct strengths method to predict the bearing capacity of channels with complex edge stiffeners and stiffeners in the web, it will make the excessively conservative results to the test data for it couldn't account for the interaction between distortional and local buckling. In order to study the method for bearing capacity of channels with complex edge stiffeners and web stiffeners under axial compression, the paper revised the current direct strengths method and new proposals considered distortional and local interaction buckling were made. The proposed method was verified by the finite element analysis results and the test results. It shows that the member strength predicted by the proposed method is more accurate than the present method and agrees well with the test data. Furthermore, compared with the results of the finite element method and hand method, the hand method for calculating elastic buckling critical stress of web-stiffened lipped channels with complex edge stiffeners was validated.
\end{abstract}

\section{Introduction}

Cold-formed steel sections are commonly used in a variety of applications including residential construction. With the reduction in thickness and variation in sections, distortional buckling modes have become control actions in structural instabilities gradually. Effective width method is the common approach in current codes for all countries, but the process of calculation is too complicated and the influence of distortional buckling is not considered. Direct strength method (DSM) developed recently is able to handle both local and distortional effects and has simple but accurate calculation. However, its application to members affected by distortional-local interaction buckling is still under development. Widely accepted DSM for channels with complex edge stiffeners and web stiffeners is lacking.

In recent years, the study on calculation method of the stiffened members' bearing capacity has been carried out in China and abroad. But about channels with complex edge stiffeners and web stiffeners under axial compression, there is no well established method. The paper deals with the ultimate strength and design of pin-ended channel columns with complex edge

\footnotetext{
* Corresponding author: ralphsy@163.com
} 
stiffeners and web stiffeners under axial compression. The aim of this paper is to put forward a method considered distortional-local interaction buckling.

\section{Current Direct Strength Method}

The DSM provides an efficient approach to estimate the ultimate strength of cold-formed steel columns considered failing in local-global interactive and distortional-global interactive modes[1]. The formula for calculation is as follows.

$$
P_{\mathrm{n} l}=\left\{\begin{array}{cr}
P_{\mathrm{ne}} & \lambda_{l} \leq 0.776 \\
{\left[1-0.15\left(\frac{P_{\mathrm{cr} l}}{P_{\mathrm{ne}}}\right)^{0.4}\right]\left(\frac{P_{\mathrm{cr} l}}{P_{\mathrm{ne}}}\right)^{0.4} P_{\mathrm{ne}}} & \lambda_{l}>0.776
\end{array}\right.
$$

where $\lambda_{l}=\sqrt{P_{\mathrm{ne}} / P_{\mathrm{crl}}} ; \quad P_{\mathrm{cr} l}=A \sigma_{\mathrm{crl}} ;$ and $\sigma_{\mathrm{crl}}$ means local critical buckling stresses; $P_{\mathrm{ne}}$ means overall stability bearing capacity.

$$
P_{\mathrm{nd}}=\left\{\begin{array}{cc}
P_{\mathrm{ne}} & \lambda_{\mathrm{d}} \leq 0.561 \\
{\left[1-0.25\left(\frac{P_{\mathrm{crd}}}{P_{\mathrm{ne}}}\right)^{0.6}\right]\left(\frac{P_{\mathrm{crd}}}{P_{\mathrm{ne}}}\right)^{0.6} P_{\mathrm{ne}}} & \lambda_{\mathrm{d}}>0.561
\end{array}\right.
$$

where $\lambda_{\mathrm{d}}=\sqrt{P_{\mathrm{ne}} / P_{\text {crd }}} ; P_{\text {crd }}=A \sigma_{\text {crd }} ; \sigma_{\text {crd }}$ means distortional critical buckling stresses.

The column nominal strength is the lower of the local-global interactive and distortional-global interactive failure stresses.

The domestic method considered local-global interaction buckling [2] is determined by

$$
P_{\mathrm{nl}}=\left\{\begin{array}{cc}
P_{\mathrm{ne}} & \lambda_{l} \leq 0.847 \\
{\left[1-0.10\left(\frac{P_{\mathrm{crl}}}{P_{\mathrm{ne}}}\right)^{0.36}\right]\left(\frac{P_{\mathrm{crl}}}{P_{\mathrm{ne}}}\right)^{0.36} P_{\mathrm{ne}}} & \lambda_{l}>0.847
\end{array}\right.
$$

The domestic method considered distortional-global interaction buckling is identical to Eq. 2, but the integral stability coefficient of specimen is determined by domestic code.

The current method only considered local-global interactive and distortional-global interactive buckling, but the buckling mode of specimen with web stiffener mostly is interaction of local, distortional and overall buckling modes. The formula proposed by Yap [3] is suitable for fixed-ended lipped channel columns, but for pin-ended complex lipped channel it is necessary to study the direct strength method of the bearing capacity of channels with complex edge stiffeners and web stiffeners under axial compression. 


\section{The Elastic Buckling Stress of Channels with Complex Edge Stiffeners and Web Stiffeners}

The elastic buckling stress is essential for the calculation of direct strength method. The finite strip program of CUFSM was used to calculate the elastic buckling stress of channel columns with complex edge stiffeners and web stiffeners under axial compression. The results of the finite strip and hand methods were compared with each other, and the hand method of elastic buckling critical stress was validated. The buckling stress of channels with complex edge stiffeners and interactive $\mathrm{V}$ type stiffeners has been studied by Wang Chungang [4] and with complex edge stiffeners and interactive $\sum$ type stiffeners was studied in this paper.

The cross section forms used for analysis are shown in Fig.1. There are three kind of specimen length $(L=1 \mathrm{~m}, 2 \mathrm{~m}, 3 \mathrm{~m})$; two kind of thickness $(t=1 \mathrm{~mm}, 2 \mathrm{~mm})$; two kind of web height $(H=180 \mathrm{~mm} 、 220 \mathrm{~mm}) ; E=2.06 \times 10^{5} \mathrm{MPa} ; v=0.3 ; f_{\mathrm{y}}=345 \mathrm{MPa}$; the flange width $B=90 \mathrm{~mm}$, the first lip width $d=25 \mathrm{~mm}$, the second lip width $a=15 \mathrm{~mm}$. In the specimen label, C2 means channels with complex edge stiffeners and interactive $\sum$ type stiffeners and C3 means with complex edge stiffeners and interactive $\mathrm{V}$ type stiffeners. $\mathrm{L}$ and the number then represents effective length; the letter s and h means $H=180 \mathrm{~mm}, H=220 \mathrm{~mm}$ respectively; the number 1 and 2 means $t=1 \mathrm{~mm}, t=2 \mathrm{~mm}$; the letter a to e in $\mathrm{C} 2$ section means $H_{1} / H_{2}=0.5,1.0$, $1.5,2.0,3.0$ and a, b in C3 section means $s=20 \mathrm{~mm}, 26 \mathrm{~mm}$.

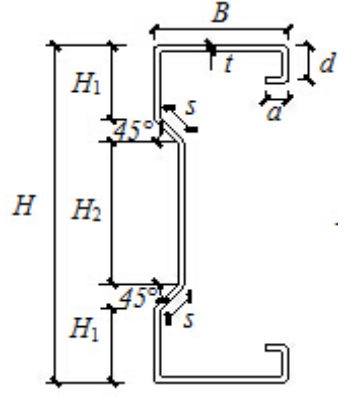

a) $\mathrm{C} 2$

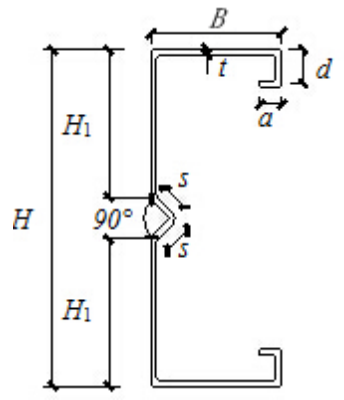

b) $\mathrm{C} 3$

Fig. 1 Cross section form and geometric parameters definition of test specimen

\section{The local buckling stress}

The hand method of elastic local buckling stress proposed by Schafer [5] is suited for channels with interactive $\mathrm{V}$ type stiffeners. As shown in Table 1, the results of hand method coincided with the analysis results approximately, and the elastic local buckling critical stress of channels with $\sum$ type section is also predicted by this simplified formula.

Table 1 The Elastic Local Buckling Critical Stress Of Channels With $\sum$ Type Section

\begin{tabular}{|c|c|c|c|}
\hline \multirow{2}{*}{ Specimen } & Schafer & CUSFM & \multirow{2}{*}{$\sigma_{\mathrm{cr} l} / \sigma_{\mathrm{cr} l}{ }^{\prime}$} \\
\cline { 2 - 3 } & $\sigma_{\mathrm{crl}} / \mathrm{MPa}$ & $\sigma_{\mathrm{crl}}{ }^{\prime} / \mathrm{MPa}$ & 0.945 \\
\hline C2L1000s1a & 124.95 & 132.25 & 0.959 \\
\hline C2L1000s2a & 499.81 & 521.39 & 0.970 \\
\hline C2L1000h1a & 118.03 & 121.67 & 0.993 \\
\hline C2L1000h2a & 472.12 & 475.29 & 0.908 \\
\hline C2L1000s1b & 116.34 & 128.12 & \\
\hline
\end{tabular}




\begin{tabular}{|c|c|c|c|}
\hline C2L1000s2b & 465.35 & 514.23 & 0.905 \\
\hline C2L1000h1b & 108.63 & 125.59 & 0.865 \\
\hline C2L1000h2b & 434.52 & 500.23 & 0.869 \\
\hline C2L1000s1c & 118.64 & 128.97 & 0.920 \\
\hline C2L1000s2c & 450.15 & 509.95 & 0.883 \\
\hline C2L1000h1c & 112.27 & 125.54 & 0.894 \\
\hline C2L1000h2c & 449.08 & 496.67 & 0.904 \\
\hline C2L1000s1d & 124.20 & 128.27 & 0.968 \\
\hline C2L1000s2d & 496.79 & 507.24 & 0.979 \\
\hline C2L1000h1d & 118.37 & 123.80 & 0.956 \\
\hline C2L1000h2d & 473.48 & 489.79 & 0.967 \\
\hline C2L1000s1e & 131.69 & 127.36 & 1.034 \\
\hline C2L1000s2e & 526.78 & 503.72 & 1.046 \\
\hline C2L1000h1e & 126.73 & 120.83 & 1.049 \\
\hline C2L1000h2e & 506.41 & 476.41 & 1.063 \\
\hline Average & & & 0.954 \\
\hline StDev & & & 0.061 \\
\hline
\end{tabular}

Table 2 The Elastic Distortional Buckling Critical Stress Of Channels With $\Sigma$ Type Section

\begin{tabular}{|c|c|c|c|}
\hline \multirow{2}{*}{ Specimen } & Hancock & CUSFM & \multirow{2}{*}{$\sigma_{\text {crd }} / \sigma_{\text {crd }}{ }^{\prime}$} \\
\cline { 2 - 3 } & $\sigma_{\text {crd }} / \mathrm{MPa}$ & $\sigma_{\text {crd }}{ }^{\prime} / \mathrm{MPa}$ & 0.970 \\
\hline C2L1000s1a & 134.57 & 138.80 & 1.012 \\
\hline C2L1000s2a & 291.64 & 288.24 & 1.031 \\
\hline C2L1000h1a & 117.76 & 114.22 & 1.068 \\
\hline C2L1000h2a & 254.04 & 237.84 & 0.973 \\
\hline C2L1000s1b & 134.57 & 138.37 & 1.015 \\
\hline C2L1000s2b & 291.64 & 287.35 & 1.028 \\
\hline C2L1000h1b & 117.76 & 114.58 & 1.065 \\
\hline C2L1000h2b & 254.04 & 238.49 & 0.978 \\
\hline C2L1000s1c & 134.57 & 137.56 & 1.021 \\
\hline C2L1000s2c & 291.64 & 285.55 & 1.036 \\
\hline C2L1000h1c & 117.76 & 113.64 & 1.074 \\
\hline C2L1000h2c & 254.04 & 236.57 & 0.983 \\
\hline C2L1000s1d & 134.57 & 136.91 & 1.026 \\
\hline C2L1000s2d & 291.64 & 284.13 & 1.045 \\
\hline C2L1000h1d & 117.76 & 112.73 & 1.082 \\
\hline C2L1000h2d & 254.04 & 234.71 & 0.989 \\
\hline C2L1000s1e & 134.57 & 136.04 & 1.033 \\
\hline C2L1000s2e & 291.64 & 282.20 & 1.057 \\
\hline C2L1000h1e & 117.76 & 111.42 & 1.029 \\
\hline Average & & & 0.037 \\
\hline StDev & & & \\
\hline
\end{tabular}




\section{The distortional buckling stress}

It is found that the influence of the interactive $\mathrm{V}$ type stiffener on the distortional stress of the section is very small. The formula proposed by Hancock [6] is suited for channels with interactive $\mathrm{V}$ type stiffeners. The comparison result of distortional stress of channels with $\Sigma$ type section calculated by hand method and software analysis is shown in Table 2 .

\section{The Global Buckling Stress}

Setting up the middle stiffeners doesn't have a significant effect on the overall stability. The method of global buckling stress was introduced in literature [7].

\subsection{Proposed Design Method for bearing capacity of channels with complex edge stiffeners and web stiffeners under axial compression}

As shown in Table 3. Using present direct strengths method to predict the bearing capacity of channels with complex edge stiffeners and stiffeners in the web, it will make the excessively conservative results to the test data.

In order to consider the enhancement of bearing capacity by stiffening, the magnification factor has been introduced into $P_{\mathrm{nd}} \cdot \sqrt{P_{\mathrm{uf}} / P_{\mathrm{nd}}}$ is used as ordinate and $P_{\mathrm{n} l} / P_{\text {crd }}$ is used as abscissa. The results are showed in Fig2. It's obvious that regularities of distribution seem to be linear. The fitting equation is: $y=0.04527 x+1.12599$, recommended formula: $y=0.045 x+1.1$.

Table 3 The Results Of The Present Dsm Contrast To The Experimental Results

\begin{tabular}{|c|c|c|c|c|c|}
\hline Specimen & $P_{\mathrm{ut}} / \mathrm{kN}$ & $P_{\mathrm{n} /} / \mathrm{kN}$ & $P_{\mathrm{nd}} / \mathrm{kN}$ & $P_{\mathrm{n}} / \mathrm{kN}$ & $P_{\mathrm{ut}} / P_{\mathrm{n}}$ \\
\hline C2L700b & 296.25 & 327.14 & 210.35 & 210.35 & 1.408 \\
\hline C3L700a & 296.67 & 311.83 & 203.13 & 203.13 & 1.460 \\
\hline C3L700b & 294.14 & 312.56 & 205.08 & 205.08 & 1.434 \\
\hline C2L1250a & 302.72 & 303.82 & 201.85 & 201.85 & 1.500 \\
\hline C3L1250a & 255.47 & 296.89 & 196.64 & 196.64 & 1.299 \\
\hline C3L1250b & 275.80 & 296.99 & 196.25 & 196.25 & 1.405 \\
\hline C2L1800a & 215.75 & 269.85 & 189.70 & 189.70 & 1.137 \\
\hline C2L1800b & 271.34 & 267.75 & 188.28 & 188.28 & 1.441 \\
\hline C3L1800a & 243.38 & 273.76 & 184.42 & 184.42 & 1.320 \\
\hline C3L1800b & 236.62 & 272.78 & 184.73 & 184.73 & 1.281 \\
\hline Average & & & & & 1.415 \\
\hline StDev & & & & & 0.147 \\
\hline
\end{tabular}

Table 4 Proposed Method Contrast To Test Results

\begin{tabular}{|c|c|c|c|}
\hline Specimen & $P_{\mathrm{ut}} / \mathrm{kN}$ & $P_{\mathrm{m}} / \mathrm{kN}$ & $P_{\mathrm{ut}} / P_{\mathrm{m}}$ \\
\hline C2L700a & 351.06 & 304.09 & 1.154 \\
\hline C2L700b & 296.25 & 302.65 & 0.979 \\
\hline C3L700a & 296.67 & 292.84 & 1.013 \\
\hline C3L700b & 294.14 & 295.06 & 0.997 \\
\hline C2L1250a & 302.72 & 291.50 & 1.038 \\
\hline C2L1250b & 330.54 & 291.83 & 1.133 \\
\hline
\end{tabular}




\begin{tabular}{|c|c|c|c|}
\hline C3L1250a & 255.47 & 283.50 & 0.901 \\
\hline C3L1250b & 275.8 & 283.06 & 0.974 \\
\hline C2L1800a & 215.75 & 277.52 & 0.777 \\
\hline C2L1800b & 271.34 & 276.25 & 0.982 \\
\hline C3L1800a & 243.38 & 270.39 & 0.900 \\
\hline C3L1800b & 236.62 & 270.96 & 0.873 \\
\hline Average & & & 0.977 \\
\hline StDev & & & 0.106 \\
\hline
\end{tabular}

Table 5 Proposed Method Contrast To Fea Results

\begin{tabular}{|c|c|c|c|}
\hline Specimen & $P_{\mathrm{u}} / \mathrm{kN}$ & $P_{\mathrm{m}} / \mathrm{kN}$ & $P_{\mathrm{u}} / P_{\mathrm{m}}$ \\
\hline C2L1000s1a & 97.15 & 95.11 & 1.021 \\
\hline C2L2000s1a & 76.87 & 85.95 & 0.894 \\
\hline C2L1000h2a & 280.15 & 268.59 & 1.043 \\
\hline C2L2000h1a & 85.66 & 90.14 & 0.950 \\
\hline C2L2000h2a & 253.51 & 241.77 & 1.049 \\
\hline C2L3000h2a & 183.05 & 179.52 & 1.020 \\
\hline C2L1000s1b & 96.47 & 94.71 & 1.019 \\
\hline C2L2000s2b & 254.55 & 238.04 & 1.069 \\
\hline C2L1000h2b & 283.45 & 269.37 & 1.052 \\
\hline C2L2000h1b & 87.26 & 91.84 & 0.950 \\
\hline C2L2000h2b & 256.58 & 243.52 & 1.054 \\
\hline C2L3000h1b & 78.13 & 74.22 & 1.053 \\
\hline C2L3000h2b & 186.41 & 183.88 & 1.014 \\
\hline C2L1000s1c & 96.47 & 94.50 & 1.021 \\
\hline C2L2000s1c & 74.77 & 85.95 & 0.870 \\
\hline C2L2000s2c & 210.78 & 238.95 & 0.882 \\
\hline C2L1000h1c & 106.57 & 99.93 & 1.066 \\
\hline C2L1000h2c & 285.23 & 269.07 & 1.060 \\
\hline C2L2000h1c & 86.12 & 91.76 & 0.939 \\
\hline C2L2000h2c & 255.62 & 243.78 & 1.049 \\
\hline C2L3000h1c & 78.86 & 74.43 & 1.060 \\
\hline C2L3000h2c & 187.12 & 186.03 & 1.006 \\
\hline C3L1000h1a & 103.52 & 96.13 & 1.077 \\
\hline C3L1000h2a & 279.66 & 264.80 & 1.056 \\
\hline C3L2000h1a & 87.39 & 87.71 & 0.996 \\
\hline C3L1000s1a & 93.89 & 93.49 & 1.004 \\
\hline C3L1000s2d & 281.26 & 265.14 & 1.061 \\
\hline C3L1000h2d & 230.43 & 267.74 & 0.861 \\
\hline Average & & & 1.007 \\
\hline StDev & & & 0.065 \\
\hline
\end{tabular}


The proposed design methods for bearing capacity are as follows:

$$
P_{\mathrm{n} l \mathrm{~d}}=\gamma P_{\mathrm{nd}}
$$

where $\gamma=\left(0.045 \lambda_{l d}^{2}+1.1\right)^{2} ; \lambda_{l d}=\sqrt{P_{\mathrm{n} l} / P_{\mathrm{crd}}} ; P_{\mathrm{n} l}$ and $P_{\mathrm{nd}}$ are obtained from Eq. 2 and Eq. 3.

The column nominal strength $\left(P_{\mathrm{n}}\right)$ is the lower of $P_{\mathrm{n} l}$ and $P_{\mathrm{n} / \mathrm{d}}$.

In order to validate the accuracy of proposed method, the proposed method is verified by the finite element analysis results and the test results from literature [8]. As shown in Table 4 and Table 5. The contrast results are in good agreement.

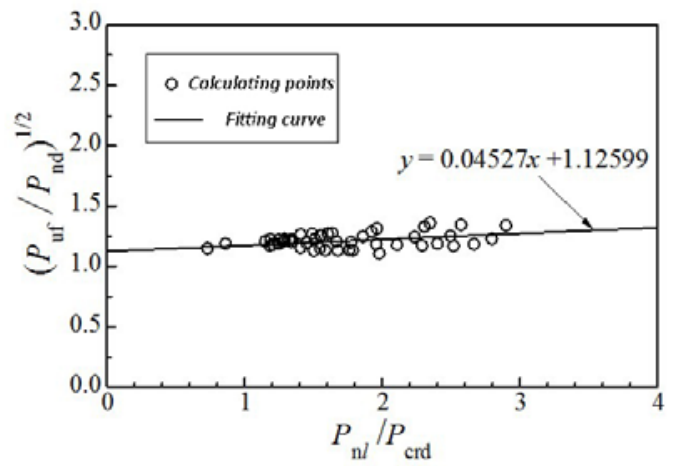

Fig.2 Curve fit

\section{Summary}

(1) The hand methods of the elastic local and distortional buckling stress are also suited for the channels with complex edge stiffeners and web stiffeners.

(2) The ultimate bearing capacity of the members can be improved effectively after stiffening and the failure mode mainly are distortional or distortional-local interactive buckling. The result of the present direct strength method is often inaccurate and conservative.

(3) Based on the current DSM, a method considered distortional-local interaction buckling for bearing capacity of channels with complex edge stiffeners and web stiffeners under axial compression was proposed and verified by the finite element analysis results and the test results.

\section{Acknowledgements}

This work described in this paper was supported by Natural Science Foundation of Liaoning Province (2015020575), their supports are gratefully acknowledged. 


\section{References}

1. Hancock G J, Murray T M, Ellifritt D S. Cold-formed steel structures to the AISI specification[M]. New York: Marcel Dekker, 2001.

2. Wang Chungang, Zhang Zhuangnan, Zhang Yaochun. Direct strength method study on bearing capacity calculation of channel columns with inclined simple edge stiffeners under axial compression[J]. Engineering Mechanics, 2012, 29(3): 75-82.

3. Yap D C Y, Hancock G J. Experimental study of high-strength cold-formed stiffened-web C-sections in compression[J]. Journal of Structural Engineering, 2011, 137(2):162-172.

4. Wang Chungang, Zhang Zhuangnan, Jia Lianguang, Ma Ping. Stability behavior research of channels with complex edge stiffeners and intermediate $\mathrm{V}$ type stiffeners under axial compression[J]. Engineering Mechanics, 2012, 29(SII): 113-116.

5. Schafer B W. Local, distortional, and Euler buckling of thin-walled columns [J]. Journal of Structural Engineering, 2002, 128(3): 289-99.

6. Lau S C W, Hancock G J. Distortional buckling formulas for channel columns[J]. Journal of Structural Engineering, 1987, 113(5): 1063-1078.

7. Chen Ji. Stability of steel structures theory and design[M]. 5rd Edition. Beijing: Science Press, 2011.

8. Wang Chungang, Xu Zifeng, Zhang Zhuangnan, Ma Ping. Experimental investigation on channel columns with complex edge stiffeners and stiffeners in web under compression loading[J]. Journal of Building Structures, 2014, 35(7): 96-104. 